\title{
A FRAMEWORK TO ENHANCE THE DESIGN OF REFLECTIVE LEADERSHIP DEVELOPMENT LEARNING INTERVENTIONS ${ }^{1}$
}

\author{
P. Harry-Nana* \\ e-mail: pharrynana@gmail.com
}

\author{
A. Bosch* \\ e-mail: abosch@sun.ac.za / http://orcid.org/0000-0002-6865-5439 \\ *University of Stellenbosch Business School \\ Stellenbosch, South Africa
}

ABSTRACT

As workplaces grow more complex and multicultural, the need for a reflective leader has been identified as a key skill in the development of leaders. Business schools provide reflective leadership development learning interventions often with little empirical work to inform curriculum development. This study aimed to describe the perceived value of reflective learning in the leadership development of business students and how these insights could inform the design of leadership development interventions. Convenience sampling was employed through the use of social media. Primary data were collected via a questionnaire and follow-up interviews. The data showed that reflective learning did add value to participants during leadership development and that life story or autobiographical reflections were the most popular intervention types. The main findings emphasise the importance of taking prior reflective experiences, readiness and learning preferences of students into account when including reflective learning in leadership development interventions. These findings guided the development of a framework to enhance the design of reflective leadership development learning interventions. Such a framework can be used by higher education educators in the quest to cultivate the skill of reflection in leaders.

Keywords: teaching tool, business school, leadership development, prior reflection, learner readiness

\section{INTRODUCTION}

With reflection named as one of the key competencies required for effective leadership, the concept of the reflective leader becomes relevant in our ever-changing business environment (George 2007; Roberts 2008). The need to develop reflective leaders for the future has significant implications within higher education, especially concerning the business and leadership education of students (Light and De Dea Roglio 2009; Rubens et al. 2018). If business schools have a key role to play in producing reflective leaders, curricula should include strategies to cultivate students' reflective ability (Densten and Gray 2001; Hay, Peltier and 
Drago 2004; Light and De Dea Roglio 2009; Rubens et al. 2018). According to Morrison (1996), students who engage in reflective activities report increased self-awareness, selfconfidence and feelings of empowerment. Yet, many graduates go through their business education programme having never been prompted to do introspective assessments of themselves (Rubens et al. 2018). Educators should not only contemplate how to design interventions to include ethical approaches that match real-life needs (Bennis and O' Toole 2005), but also how to conduct these interventions over a period of time in an iterative rhythm (Doh 2003; Kayes 2002) whilst also giving the practice of reflection centre stage (Nahavandi 2006). There is a both a need and demand for further research, given the paucity of literature and theoretical guidance on teaching reflective learning in higher education business programmes (Ryan and Ryan 2013) and, despite positive findings, the large pool of inconclusive evidence (Shamir and Eilam 2005) regarding its value. Shay $(2017,5)$ calls to attention that higher education needs to make "significant educational investment into improving the effectiveness of teaching and learning". This study therefore set out to explore how business students perceived the value of reflective learning interventions within leadership development courses. We argue that student perceptions may contribute to the development of a framework to enhance the use of reflection during the teaching of leadership development.

The article commences by defining reflective learning and reviewing both the different approaches to reflective learning and the value that has been reported about it in higher education contexts. Next, leadership development is explicated, providing discussion about the role and importance of reflective learning towards the development of reflective leaders. The method and findings are provided which culminate in understanding the perceived value of reflective learning in leadership development. Findings also contribute to a tool for the enhancement of the design of reflective interventions during leadership development.

\section{REFLECTIVE LEARNING}

Reflective learning is multi-faceted and based on independent internalised realisations and personal experience. It is defined as intellectual and affective activities that allow an individual to explore their experiences leading to new appreciations, understandings or evaluations (Boyd and Fales 1983; Castelli 2011; Fakude and Bruce 2003). Goleman, Boyatzis and McKee (2002) suggest that self-directed learning, using reflective questioning, has proven to be effective for developing emotional intelligence and ultimately, leadership skill. However, some proponents, such as Brookfield (2017), believe that reflection relates directly to how effectively individuals can and are willing to learn from their personal experiences. Yet, by encouraging students to question and change their personal notions through a structured leadership development 
programme, critical reflection can broaden perspectives which can lead to a more holistic understanding of complex scenarios (Densten and Gray 2001; Fakude and Bruce 2003; Kayes 2002). In addition, Morrison (1996) shows that students are able to assemble a comprehensive understanding of their whole self, including personal, interpersonal, intellectual, professional, private, and the public aspects.

Significant research expanded and formalised the notion of reflective learning over the years in the adult and higher education fields (Castelli 2011; Mezirow 1998; Schön 1983, 1987; Taylor 2007). In addition, many educators have found integrative ways to apply reflective learning in classrooms (Carson and Fisher 2006; Cranton 2002; 2006; Fisher-Yoshida 2009). Ryan $(2013$, 145) encourages the teaching of reflection in "deep, critical and transformative ways". Transformative ways of teaching include interventions such as Leadership 360-degree assessments, where three levels of people that know the leader and has interacted with them before namely, manager, colleague and subordinate levels, provide structured feedback about the leader. Other interventions are leadership interviews where students interview a senior leader using a structured questionnaire, leadership development exercises incorporating case studies, autobiographical work including the writing of life stories, journaling and selfassessments and practices that challenge students' values, beliefs and assumptions such as dialogue and exchange on a topic.

Despite evidence for the value of reflective learning in education, the practice of reflection is often new to students, resulting in them having difficulty with reflecting critically (Smith 2001). Engaging in critical reflection can thus lead to the creation of student discomfort and dissonance (Densten and Gray 2001) such as when students gain insights about their leadership behaviour and its underlying motives which may challenge their own deeply held beliefs about themselves. More so, reflection is a complex, emotional and intellectual process that takes time to do well or could even lead to being superficial unless higher education interventions are approached in a planned and thoughtful way. Ryan and Ryan $(2013,244)$ concur with Bain et al. (2002) "that deep reflective skills can be taught but this requires development and practice over time".

Much of the literature on reflective learning is concerned with how and at what level learners reflect (Bain et al. 2002; Mezirow 2006). Hay, Peltier and Drago (2004) state that reflection is more than just a process and has been conceptualized across a number of levels.

A framework, produced by Peltier et al. (2005), as depicted in Figure 1, which is also based on the work developed by Mezirow (1991) followed by Leung and Kember (2003) and Kember, Biggs and Leung (2004), describes four levels of reflection based on a continuum that ranges from non-reflective surface learning to intensive deep reflection. According to Peltier et 


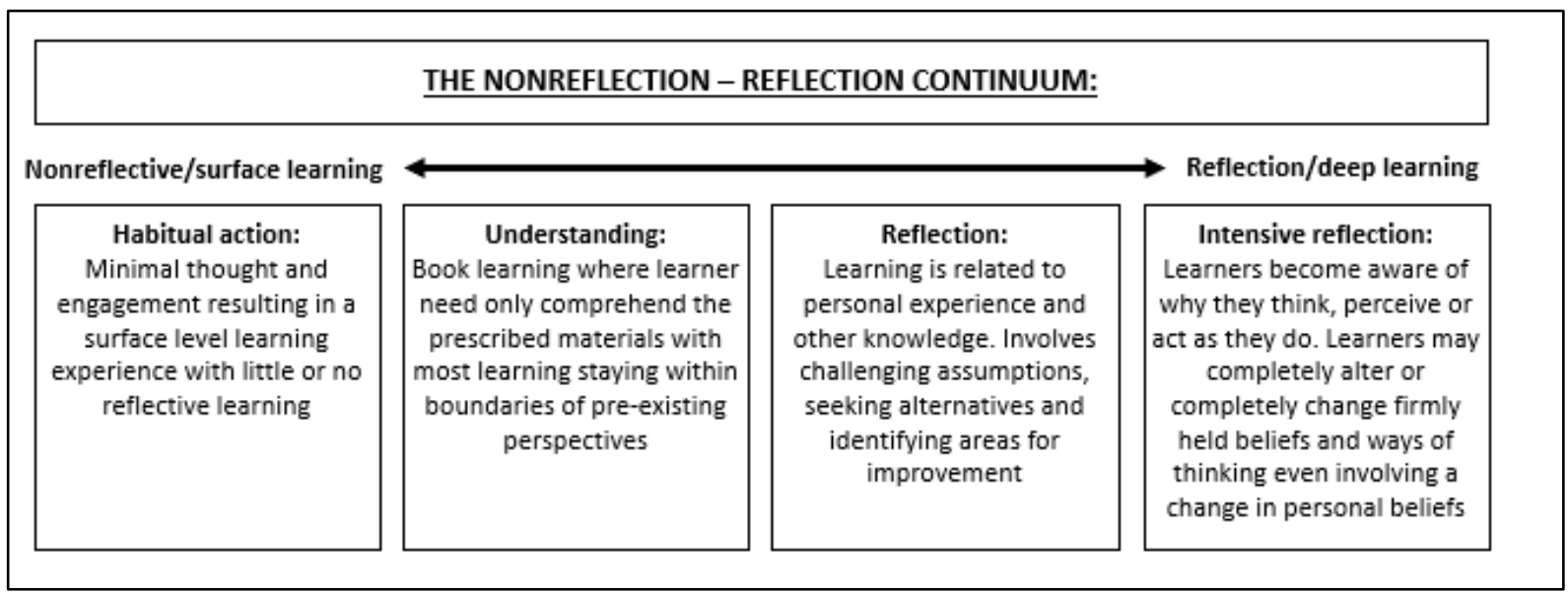

Figure 1: The adapted nonreflection-reflection continuum from Peltier, Hay and Drago (2005)

al. (2005), the lowest level of the reflection hierarchy is habitual action learning and is usually non-reflective. This is followed by the level of understanding which is non-reflective and is followed by reflection and intensive reflection, both of which encompass deep and thoughtful learner traits. Higher levels of reflection upon the hierarchy lead to more effective learning, and as such, it is suggested that intensive reflection ought to become a common aim in educational programmes (Peltier et al. 2005).

\section{REFLECTIVE LEADERSHIP DEVELOPMENT AND HIGHER EDUCATION}

Leadership development is an important imperative in higher education settings as universities contribute to building societies and to addressing issues of social equity (Marginson 2018). Leaders are expected to engage and mobilise followers to act on new ideas and challenge conventional thinking (Densten and Gray 2001) therefore there has been growing popularity in leadership studies in undergraduate, graduate and executive education programmes. Leadership development addresses issues about the self as leader as well as leader behaviour (Shamir and Eilam 2005) and provide opportunities for the development of individuals' leadership attributes. Attributes such as self-awareness, self-knowledge and self-regulation are central to effective leadership (Branson 2007; Gardner et al. 2005; George 2007), therefore students are encouraged to gain deeper self-awareness through interventions that enable reflection (Avolio and Gardner 2005; Roberts 2008; Riggio 2008). Interventions range from individual-centered activities, including journaling to peer discussions and group dialogue. Interventions can also consist of structured activities, where instructions are supplied to guide reflection such as in the case of self and peer assessments, or they can be more unstructured, such as autobiographical work including the writing of life stories, keeping journals or even the writing of one's obituary. 
In the latter case, the activity has an instruction at the onset but reflection on the outcome may be less structured or could be followed by an unstructured dialogue with a staff member that is led by the student.

Schön (1987) states that reflective learning seems to be of particular importance in the context of business education. People want leaders to live by virtue, resulting in the need for leadership that is authentic, ethical and genuine to contend with today's ambiguous, chaotic and turbulent environment (Branson, 2007; Gardner et al. 2005; George 2007). The ability to reflect has been seen as a critical element to effective management and leadership decision making, especially in environments with no defined solutions and unique, ever-changing elements (Schön, 1983; 1987). If a higher education teacher aim to nurture effective leaders, courses should include strategies for leadership skills development including cultivating students' reflective ability (Densten and Gray 2001; Hay, Peltier, and Drago 2004; Rubens et al. 2018). In this regard reflective learning is defined as "... the process of internally examining and exploring an issue of concern, triggered by an experience, which creates and clarifies meaning in terms of self, and which results in a changed conceptual perspective" (Boyd and Fales 1983, 99). Curricula should therefore focus on reflective learning that assist future leaders to adopt more sophisticated self-monitoring behaviours (Densten and Gray 2001). This is imperative, not only to the short-term success of graduate business students, but also to their long-term career success in business (Rubens et al. 2018).

In order to determine both the value of reflective learning interventions during leadership development and gain insights to the improvement of the teaching of reflective practices during leadership development, we wanted to answer the question: "What is the perceived value of reflective learning in the leadership development of students? " Secondary questions were:

a. Which reflective learning interventions added value to students?

b. What level of depth of reflection do the students report?

c. Which benefits did the students gain from reflective learning?

\section{METHOD}

This descriptive study utilised an online questionnaire and follow-up interviews to collect primary data.

\section{Sampling}

Convenience non-probability sampling (Vogt 2005) was employed with screening of potential participants to confirm eligibility (Lavrakas 2008). We targeted Masters of Business 
Administration (MBA) students that were busy with or had completed their degree, but in all cases had completed a leadership development module in the past five years. All institutions included in the dataset assert that leadership development is a key component of their curriculum and employ reflective interventions including journaling and peer-assessments for this purpose. Students were not primed about the nature, or depth of reflection but the topic of reflection was linked to interventions through study material, intervention guidelines and reference to reflection in classroom settings. Data was collected in October 2018. In addition, snowball sampling was employed by asking participants to forward the call for participation to other people that met the inclusion criteria (Zikmund et al. 2010). A total number of 40 people participated. Three of these were pilot test participants and were thus not included in the results. Subsequent to completing the questionnaire, three participants were interviewed to facilitate improved understanding of their data.

\section{Sample description}

Twenty-four of the 37 participants were male and the balance indicated that they were female. The ages ranged from the youngest at 27 years old to the oldest participant being 51 years. The median age of the participants was 35.78 years. The racial profile consisted of 16 White, 10 African, 6 Coloured, and 5 Indian/Asian, as described in the official South African race classification system. Four business schools were represented.

\section{Data collection tools}

\section{Questionnaire}

The online questionnaire contained screening questions to ensure that the correct target sample was reached. Screening questions were followed by three questions which identified the value of reflective learning, the level of reflective learning as per the Peltier et al. (2005) continuum, and the types of reflective interventions considered valuable. The questions were:

1. Do you feel that reflective learning interventions i.e. life journey assignments, journaling, personal development plans, added value to your leadership development journey?

2. Select the option that best describes the level of reflective learning that you experienced during your leadership development as per the Peltier et al.'s (2005) nonreflectionreflection continuum.

3. a) Which reflective learning interventions added the most value to you? Choose from the listed techniques: Life story/autobiography journey reflection, Journaling, Personal 
development planning, Self-assessments and feedback, Peer and other assessment and feedback, Other.

The second part to the third question and the fourth question were open-ended to elicit explanations and metaphors which described value of the reflective learning to participants.

3. b) Based on your responses in question 3a, why would you say these reflective learning interventions added value to you?

4. If you could describe the value that you gained through reflective learning in your leadership development journey using a word/metaphor/symbol/phrase or analogy, what would you use?

\section{Interviews}

Telephonic interviews were conducted to clarify responses to the open-ended questions where outliers existed and to pose probing questions to participants (Given 2008) regarding their perceptions of reflective learning where necessary. The use of two data collection methods facilitated rigour (Schwandt 2007).

\section{Research procedure}

The questionnaire was piloted with three MBA students prior to mass distribution to ensure that any irregularities were identified. Minor grammatical changes were made to facilitate improved understanding.

The adapted questionnaire was placed on a secure online data collection platform. The link to complete the questionnaire was posted on a LinkedIn account where MBA students were linked. With social media growing in our everyday lives, social media tools have provided researchers with novel ways of collecting data (Sloan and Quan-Haase 2016). LinkedIn contacts were invited to share the link with prospective participants that met the inclusion criteria in their own network of contacts. No content tracking functionality was utilised on the social media platform to ensure that participants were kept anonymous (Beninger 2016).

A description of the study, as well as the rights and obligations of participants, was provided on the landing page of the online questionnaire. Consent was received from all participants which included consent for the researchers to make telephonic contact to clarify meaning during data analysis. The first round of analysis was done prior to conducting telephonic interviews with the three participants that provided outlier responses (Lavrakas 2008). A second round of interpretation of data was done before results were finalised. 


\section{Data analysis}

\section{Descriptive statistics}

The data of this study was stored on an Excel spreadsheet (Remenyi et al. 1998) as it provided functionality to sort and categorise the data into tables. Similar findings were grouped together and frequencies and percentages calculated (Byrne 2017) for the first three questions.

\section{Qualitative analysis}

Thematic analysis was used to analyse the data of the open-ended questions. Data was organised and categorised into themes (Braun and Clarke 2006) on a per-respondent basis, followed by a comparison of themes between respondents. The per-respondent analysis was deductively done labelling each theme and classification into four theoretically derived themes (based on the overview of work of Morrison 1996; Densten and Gray 2001; Fakude and Bruce 2003; Marginson 2018; Schön 1987, provided earlier in this article). Next inductive analysis was done where new themes emerged from the respondent's data. This process was repeated for each respondent. Responses were thereafter compared for all respondents, specifically looking for similarities and differences between themes. Thematic analysis was initially conducted by one researcher and subsequently verified by both researchers. This concluded the first round of analysis.

In the second round of analysis, outlier responses provided variation in respondent data which were treated as sources of contrast in comparison to the bulk of the respondents (Lavrakas 2008). The outlier responses were compared against theory in a discussion between both researchers. In addition, participants were probed for clarity about the interpretation of the open-ended questions through telephonic interviews. Findings were finalised by both researchers.

\section{Ensuring rigour}

Credibility was attained through multiple engagements with participants. This was done by participant interviews where feedback was solicited to clarify understanding (Seale 1999). The use of multiple data collection methods enabled triangulation of the data. Researcher triangulation was achieved through discussions about the themes and outlier data during data analysis (Zikmund et al. 2010). Dual researcher participation during analysis contributed towards minimising confirmation bias (Onwuegbuzie and Leech 2007). 


\section{FINDINGS}

\section{Descriptive statistics}

There was an overwhelming affirmative response to whether students felt that reflective learning interventions added value to their development as leaders, with 36 out of 37 participants answering "yes" to this question. Three participants below 30 years of age reported intense reflection and selected the life story/autobiography reflection and self- and/or peer review methods as valuable reflective interventions. The majority of the participants found value in the life story/autobiography reflection, with 26 of the 37 participants selecting this option, followed by 18 for the self- and/or peer review and assessments option and the remaining 14 for the journaling option. Participants reported that the one-on-one dialogue leadership sessions with a leadership faculty member of their Business School, which was selected by two participants, as well as meditation and discussion, were also additional reflection methods that added value to their leadership development.

All participants reported a deeper level of reflective learning, having either experienced reflection or intense reflection according to Peltier et al. (2005) nonreflection-reflection continuum. Sixteen of the 37 (43\%) participants reported that they experienced intensive reflection. This is an important finding, illustrating that reflective practices during a leadership development course had indeed added perceived value to students. The participants indicated that interventions that they favoured provided opportunities for them to undergo reflection that aids understanding of themselves and their development as leaders.

\section{Interpretation of value gained from reflective interventions}

Themes that were derived from the open ended questions are presented in Table 1.

Table 1: Themes derived for open ended questions

\begin{tabular}{|l|c|l|l|}
\hline \multicolumn{1}{|c|}{ Theoretically derived themes } & $\mathbf{n}$ & Themes inductively derived from the data & $\mathbf{N}$ \\
\hline Theme 1: Leader development & 22 & Theme 5: Enlightening & 12 \\
\hline Theme 2: Self-concept and leader identity & 15 & Theme 6: Validation and contentedness & 28 \\
\hline $\begin{array}{l}\text { Theme 3: Self-awareness and self-reflective } \\
\text { competencies }\end{array}$ & 31 & Theme 7: Shaping future behaviour & 14 \\
\hline $\begin{array}{l}\text { Theme 4: Explicit and implicit feedback as a } \\
\text { mirror }\end{array}$ & 22 & & \\
\hline
\end{tabular}

${ }^{*}$ Participants $n=37$

It is noteworthy that 31 of the 37 participants' responses were captured by theme 3, i.e. 84 per cent of the participants perceived that they had developed self-awareness and self-reflective competencies as a result of reflective interventions. Through interventions such as life story/autobiography reflection, self and/or peer review assessments and journaling, participants 
were given the opportunity to learn more about themselves including their strengths, weakness and possible areas of personal development as leaders. This was followed by theme 6 where 28 of the 37 (76\%) participants' responses were linked describing that reflective learning provided validation to them as leaders, grounding, sense making, and contentedness. This may point to reflective learning interventions allowing participants to connect aspects of themselves, their identity, to being leaders.

In the themes Leader development and Explicit and implicit feedback as a mirror, which each had 22 quotations, participants noted that the role of reflective interventions provided focus and self-understanding in their development as leaders. It also developed their ability to reflect while identifying areas for improvement and growth potential through clarifying strengths and weakness. This showed that participants were able to more clearly understand the role of reflection in their leadership development as well as how the use of explicit and implicit feedback can help themselves to learn and grow as a leader.

Participant 30 reported that $\mathrm{s} / \mathrm{he}$ had undergone some form of life-changing intensive reflection prior to the MBA, and therefore experienced reflection as opposed to intensive reflection, as contained in the nonreflection-reflection continuum. When other participants were probed about similar experiences during the telephonic interviews, they stated that under circumstances where life-changing experiences preceded the MBA, the leadership development course's reflective learning interventions were a form of validation and gaining perspective.

In question 4, participants were asked to describe what they gained from reflective learning on their leadership development journey by providing a word, metaphor, symbol or analogy as a description. The majority of participants had a positive experience of the reflective learning journey. Four themes were derived from the word/metaphor/symbol/phrase or analogy that participants provided to illustrate the value that they gained from reflective learning during leadership development (see Table 2). Theme one, two and three, relate to positive aspects whilst Theme four captures negative aspects.

Table 2: Themes indicating the value gained from reflective learning

\begin{tabular}{|l|c|l|c|}
\hline \multicolumn{1}{|c|}{ Positive themes } & $\mathbf{n}$ & \multicolumn{1}{|c|}{ Negative themes } & $\mathbf{n}$ \\
\hline Theme 1: Life-changing and transformative & 10 & Theme 4: Neutral or negative & 2 \\
\hline Theme 2: Increased self-knowledge & 19 & & \\
\hline Theme 3: Grounding and contentment & 6 & & \\
\hline
\end{tabular}

${ }^{*}$ Participants $n=37$

Theme one refers to feedback that is related to life-changing, transformative or enlightening experiences and indicates that these participants felt some sort of profound or deeper level of reflection. Examples of words or metaphors provided were: "exhilarating”, “awakening”, 
"growth" and "a caterpillar being turned into a butterfly with wings set to fly". Theme two indicated a possible increase in the level of self-identity, self-concept, self-awareness and the ability to reflect on oneself. Examples of words or metaphors provided were: "the whole me", "I learnt things about myself that I never knew existed before". There is an element of deep learning within the second theme, with participants gaining insight as well as a level of selfunderstanding and self-knowledge. The third theme represented a sense of grounding, validation and perspective gained. Examples of words or metaphors provided were: "perspective", "making sense" and "validation".

Of the 10 participants that were classed according to theme one, seven experienced an intensive level of reflection, which means that these individuals perceived that they had experienced the highest level of reflective learning and achieved greater awareness of why they think, perceive, or act as they do. Nineteen participants perceived that they had experienced increased self-knowledge as a result of the reflective interventions. Existing assumptions could thus be challenged by these participants about themselves and the world around them, as well identifying opportunities for growth.

All these cases as per themes one, two and three present positive, life changing or enhancing words that encourage growth and leadership development through the reflection of self-concept, understanding and grounding - a sense of knowing and being content. Expressions in the three positive themes, coupled with the fact that all 37 participants experienced at least a reflective level of reflection intensity or higher, as per Peltier et al.'s (2005) nonreflectionreflection continuum, underscores the importance of these findings for higher education teachers and the designers of reflective learning interventions.

Participants 2 and 23 used words such as "morbid" and "somewhat", providing neutral or negative phrases when describing the value that they gained from reflective learning. Participant 2 confirmed that despite gaining value from the reflective learning interventions, the experience was almost like death for him/her, as going to the level of depth required for the reflective learning interventions was "very challenging" and "brought up very dark emotions" that created negative emotions for the participant. The participant reported that they felt compelled to participate in reflective interventions as part of the leadership development activities that the institution provided. The participant reported that they were not ready to reflect at the required level and if the choice had been given, would have avoided reflective interventions at all costs. Participant 23 shared similar sentiments and indicated that reflective learning interventions did not match their personal learning preference style and thus chose to actively avoid these interventions.

Both these neutral and negative responses indicate a preference in learning styles away from reflection as well as not being ready to engage in reflective learning interventions. These 
findings could point to the personal development stage within these participants' lives, the propensity to avoid reflection on the past indicating reflection dissonance, or even possibly point to cultural impediments as pointed out by participant 2. Cultural impediments such as being "self-absorbed" or "egotistical" were cited and the participant therefore did not feel encouraged to engage with reflection as a leadership development activity.

\section{DISCUSSION}

Reflective learning is concerned with "... the process of internally examining and exploring an issue of concern ..." (Boyd and Fales 1983, 99) and can be harnessed through various interventions in order for students to develop as leaders. Since business environments require leaders to consider the impact and effect of their actions and decisions on followers through reflection, it is important to understand the perceived value of reflective learning in the leadership development of students. Through this understanding we can inform the design and teaching of reflective leadership development learning interventions in higher education.

Participants in this study overwhelmingly indicated that they gained value from reflective learning as part of their MBA leadership development journey. This finding is in line with the literature indicating the importance of reflective learning in the context of management education (Fakude and Bruce 2003; Kayes 2002). Utilising the reflective continuum of Peltier et al. (2005), all participants experienced a deeper, reflective level of learning, having experienced either reflection or intense reflection. Participant perceptions indicate that reflective practices helped students develop a self-concept as a leader through self-awareness. Research has generally supported a positive relationship between knowing oneself and selfawareness and overall leadership success (Goleman 2004). If the purpose of business schools is to produce effective leaders, course designs should include strategies for leadership skills development including cultivating students' reflective ability (Bailey et al. 1997; Densten and Gray 2001; Hay, Peltier and Drago 2004; Light and De Dea Roglio 2009; Rubens et al. 2018).

Different reflective strategies can be used to develop deeper or more complex levels of reflection (Ryan and Ryan 2013). In this regard participants indicated that the life narrative or autobiography reflection, the self-assessments, and journaling, were very valuable and that debriefing sessions with Business School faculty as well as class discussions were useful but to a lesser extent. Participants therefore indicated that reflective exercises involving themselves was more useful than interventions where other people were involved.

The participants who did not indicate an overwhelmingly positive response to reflection, indicated that different learning interventions would have enhanced their leadership development experience. They stated that a greater number of real-life interventions with possible learning simulations replicating real-life business situations rather than academic, 
written, or classroom setting interventions, may have enhanced their reflective development. These findings indicate that more experiential learners require different reflective interventions to suit their learning style (Pee et al. 2000). Mezirow (1998) asserts that critical reflection has the potential to integrate theory with practice, can facilitate insight, and stimulate self-discovery in professional as well as classroom settings. Higher education teachers could consider simulations of leadership scenarios, utilising assessment centres, noting that these are often costly as they involve multiple professionally trained observers.

The readiness of learners to engage with reflection, as well as the life-experiences of students which preceded their studies, may impact a learner's perception of the depth of reflection that they attained. A student's ability to engage in reflective learning initiatives may therefore be hindered or facilitated by the state of their readiness, as well as the previous life experiences of the individual. Of importance is that readiness and life experiences could ultimately affect the overall outcome and experience of a student's level of, and participation in, reflective interventions during leadership development.

A framework has been developed by incorporating the findings of this study and the reflective learning continuum of Peltier et al. (2005) (see Figure 2.) This framework should add value to designers and teachers of leadership development interventions in higher education settings.

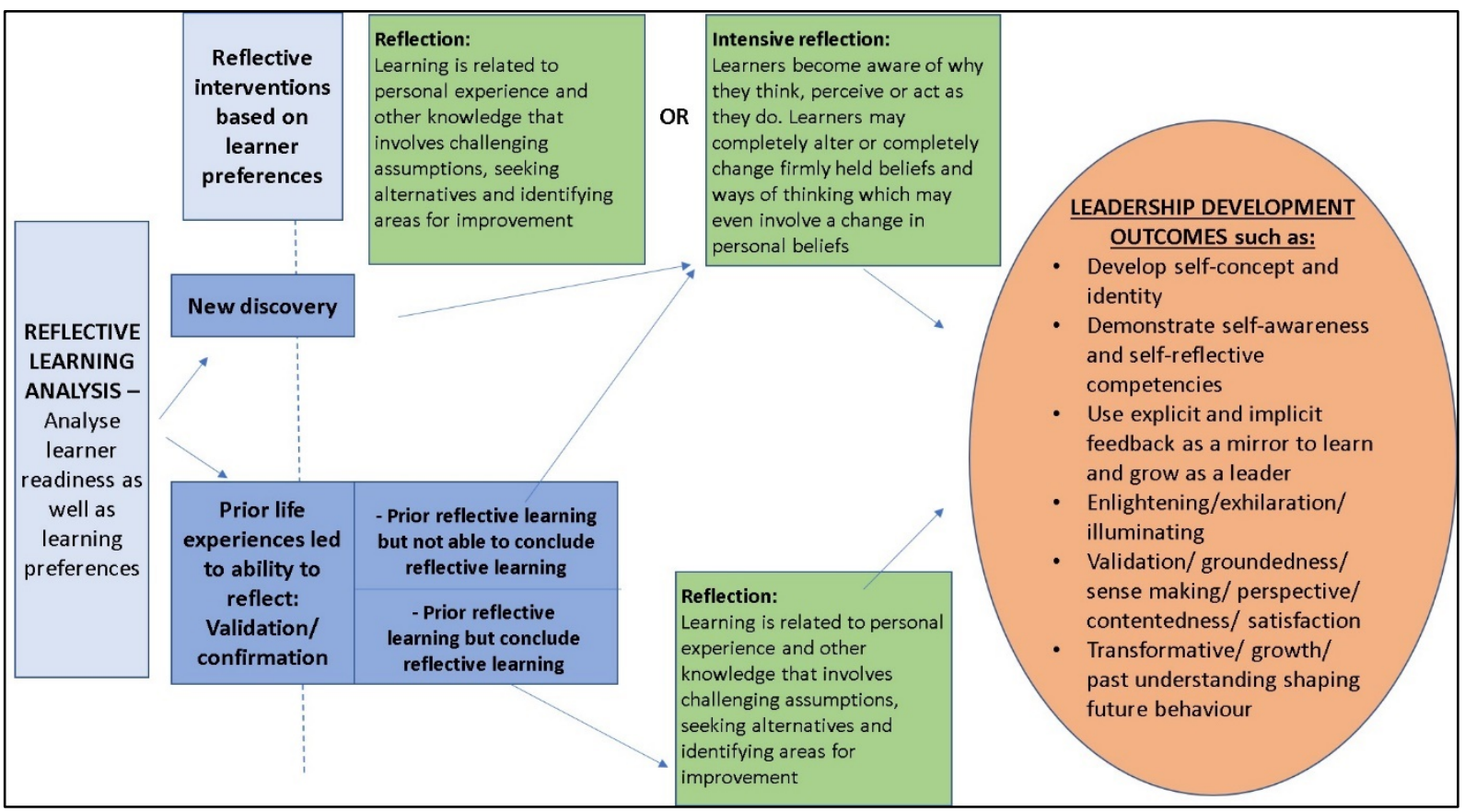

Figure 2: Framework to enhance the design of reflective leadership development learning interventions, incorporating the reflective learning continuum of Peltier et al. (2005). 
Aspects that enhance leadership development are learner readiness, learner learning style preferences as well as the exposure to previous life experiences that elicited reflection. Educators could determine these aspects prior to engaging students in reflective experiences. The reflective learning continuum is used to evaluate the depth of reflective learning that takes place during leadership development. Outcomes to leadership development will be influenced by both the readiness of students as well as the depth to which they were able to reflect.

The framework suggests that learners could follow two paths, based on whether the learning outcome is grounded on a new discovery about themselves as leaders or a previous life experience which led the student to be able to reflect and thus possibly experience an intense level of reflection prior to the leadership development intervention. All routes will lead to students likely having an increased level of value gained from reflective learning, more especially if learner preferences were determined prior to the reflective intervention and reflective activities adjusted accordingly. Intervention types should be adjusted according to the prior level of reflection of the student and their preferences.

\section{LIMITATIONS AND FUTURE RESEARCH}

The framework that is proposed in Figure 2 requires further elaboration and testing. An exploration of prior life experiences and their effect on the depth of reflection experienced during leadership development could provide important insights about the willingness of students to engage with reflective interventions, and purposing leadership development interventions to the needs of such students. The development of an instrument to determine the extent of reflection prior to a leadership development intervention and use of reflection in daily leadership practice, could contribute to improved teaching practice as interventions can be customised to meet each student according to their specific needs. Further exploratory studies of the "new" insights that participants in this study articulated, could provide ways in which opportunities for "new" insights could be purposefully designed into leadership development interventions. Although data was solicited from students at multiple business schools, participants in this study were primarily from one business school. Since participants highlighted the possibility of cultural differences hindering the uptake and practice of reflective practices, the influence of cultural differences could be explored in future studies, to provide insights about reflection in leadership development in multicultural contexts. Longitudinal studies, where the effects of reflective learning and its contribution to leadership development are tracked throughout a business course, are also suggested.

\section{CONCLUSION}

Reflective learning does indeed have a notable and positive impact on the leadership 
development of students in this study. Students not only experienced varied depth levels of reflection but were also able to articulate the value they placed on their reflective learning experience by indicating, amongst others, different preferences with regard to intervention techniques. The framework to enhance reflective learning of students compiled in this study, expands our understanding of student reflection, emphasising the importance of taking learner readiness, based on prior life reflective experience and preference, into account when including reflection in leadership development curricula. Such a framework can be used by higher education teachers to inform intervention design in the quest to cultivate the skill of reflection in leaders.

\section{NOTE}

1. Portions of the literature already appeared in an institutional assignment prior to this article.

\section{REFERENCES}

Avolio, B. J. and W. L. Gardner. 2005. Authentic leadership development: Getting to the root of positive forms of leadership. Leadership Quarterly 16(3): 315-338. doi: 10.1016/j.leaqua.2005.03.001.

Bailey, J. R., P. Saparito, K. Kressel, E. Christensen and R. Hooijberg. 1997. A model for reflective pedagogy. Journal of Management Education 21(2): 155-167.

Bain, J. D., R. Ballantyne, C. Mills and N. C. Lester. 2002. Reflecting on practice: Student teachers' perspectives. Flaxton, QLD: Post Pressed.

Beninger, K. 2016. Social media users' views on the ethics of social media research. In The SAGE handbook of social media research methods, 57-73. London: SAGE Publications. doi: $10.4135 / 9781473983847$.

Bennis, W. G. and J. O'Toole. 2005. How business schools lost their way. Harvard Business Review 83(5): 96-104. https://hbr.org/2005/05/how-business-schools-lost-their-way

Boyd, E. M. and A. W. Fales. 1983. Reflective learning: Key to learning from experience. Journal of Humanistic Psychology 23(2): 99-117.

Branson, C. 2007. Effects of structured self-reflection on the development of authentic leadership practices among Queensland primary school principals. Educational Management Administration and Leadership 35(2): 225-246. doi: 10.1177/1741143207075390.

Braun, V. and V. Clarke. 2006. Using thematic analysis in psychology. Qualitative Research in Psychology 3(2): 77-101. doi: 10.1191/1478088706qp063oa.

Brookfield, S. D. 2017. Becoming a critically reflective teacher. San Francisco, CA: Jossey-Brass.

Byrne, D. 2017. Data analysis and interpretation: Project planner. London, United Kingdom: SAGE Publications.

Castelli, P. A. 2011. An integrated model for practicing reflective learning. Academy of Educational Leadership Journal 15(Special Issue): 15-31. doi: 10.1108/17506200710779521.

Carson, L. and K. Fisher. 2006. Raising the bar on criticality: Students' critical reflection in an internship program. Journal of Management Education 30(5): 700-723. doi: 10.1177/1052562905284962.

Cranton, P. 2002. Teaching for transformation. New Directions for Adult and Continuing Education 93: 63-72. doi: 10.1002/ace.50.

Cranton, P. 2006. Understanding and promoting transformative learning: A guide for educators of adults. $2^{\text {nd }}$ Edition. San Francisco, CA: Jossey-Bass.

Densten, I. L. and J. H. Gray. 2001. Leadership development and reflection : What is the connection? 
International Journal of Educational Management 15(3): 119-124. doi: 10.1108/095135 40110384466.

Doh, J. P. 2003. Can leadership be taught? Perspectives from management educators. Academy of Management Learning \& Education 2(1): 54-67. doi: 10.5465/AMLE.2003.9324025.

Fakude, L. P. and J. C. Bruce. 2003. Journaling: A quasie-experimental study of student nurses' reflective learning ability. Curationis 26(2): 49-55. doi: 10.4102/curationis.v26i2.783.

Fisher-Yoshida, B. 2009. Coaching to transform perspective. In Transformative learning in practice: Insights from community, workplace, and higher education, ed. J. Mezirow, J. Taylor and Associates, 148-159. San Francisco, Jossey-Bass.

Gardner, W. L., B. J. Avolio, F. Luthans, D. R. May and F. Walumbwa. 2005. "Can you see the real me?" A self-based model of authentic leader and follower development. Leadership Quarterly 16(3): 343-372. doi: 10.1016/j.leaqua.2005.03.003.

George, B. 2007. True North: Discover your authentic leadership, ed. Peter Sims. $1^{\text {st }}$ Edition. San Francisco: Jossey-Bass.

Given, L. M. 2008. The SAGE Encyclopedia of qualitative research methods. Thousand Oaks, CA: SAGE Publications, Inc. doi: 10.4135/9781412963909.

Goleman, D., R. E. Boyatzis and A. McKee. 2002. Primal leadership: The hidden driver of great performance. In Harvard Business Review on breakthrough leadership, ed. D. Goleman, W. Peace, W. Pagonis, T. Peters and J. Gareth, 25-50. Boston: Harvard Business Review Press.

Goleman, D. 2004. Emotional intelligence and working with emotional intelligence: Omnibus. London: Bloomsbury.

Hay, A., J. W. Peltier and W. A. Drago. 2004. Reflective learning and on-line management education: A comparison of traditional and on-Line MBA students. Strategic Change 13(4): 169-82. doi: $10.1002 / \mathrm{jsc} .680$.

Kayes, D. C. 2002. Experiential learning and its critics: Preserving the role of experience in management learning and education. Academy of Management Learning and Education 1(2): 137-49. https://www.jstor.org/stable/40214146

Kember, D., J. Biggs and D. Leung. 2004. Examining the multidimensionality of approaches to learning through the development of a revised version of the learning process questionnaire. British Journal of Educational Psychology 74: 261-280. doi:10.1348/000709904773839879.

Lavrakas, P. J. 2008. Encyclopedia of survey research methods. Thousand Oaks, CA: Sage Publications, Inc. doi: $10.4135 / 9781412963947$.

Leung, D. and D. Kember. 2003. The relationship between approaches to learning and reflection upon practice. Educational Psychology 23(1): 61-71. doi: 10.1080/01443410303221.

Light, G. and K. De Dea Roglio. 2009. Executive MBA programs: The development of the reflective executive. Academy of Management Learning \& Education 8(2): 156-73. doi: 10.5465/ amle.2009.41788840.

Marginson, S. 2018. Public/private in higher education: A synthesis of economic and political approaches. Studies in Higher Education 43(2): 322-337. doi: 10.1080/03075079.2016.1168797.

Mezirow, J. 1991. Transformative dimensions of adult learning. San Francisco: Jossey-Bass.

Mezirow, J. 1998. On critical reflection. Adult Education Quarterly 48(3): 185-199. doi: 10.1177/074171369804800305.

Mezirow, J. 2006. An overview of transformative learning. In Lifelong learning, ed. P. Sutherland and J. Crowther, 24-38. London: Routledge.

Morrison, K. 1996. Developing reflective practice in higher degree students through a learning journal. Studies in Higher Education 21(3): 317-32. doi: 10.1080/03075079612331381241.

Nahavandi, A. 2006. Teaching leadership to first year students in a learning community. Journal of Leadership Education 5(2): 14-27. doi: 10.12806/V5/I2/AB1. 
Onwuegbuzie, A. J. and N. L. Leech. 2007. Sampling designs in qualitative research: Making the sampling process more public. The Qualitative Report 12(2). https://nsuworks. nova.edu/tqr/vol12/iss $2 / 7$

Pee, B., T. Woodman, H. Fry and E. S. Davenport. 2000. Practice-based learning: Views on the development of a reflective learning tool. Medical Education 34(9): 754-61. doi: 10.1046/j.13652923.2000.00670.x.

Peltier, J. W., A. Hay and W. Drago. 2005. The reflective learning continuum : Reflecting on reflection. Journal of Marketing Education 27(3): 250-263. doi: 10.1177/0273475305279657.

Remenyi, D., B. Williams, A. Money and E. Swartz. 1998. Doing research in business and management. London: SAGE Publications, Inc. doi: 10.4135/9781446280416.

Riggio, R., E. 2008. Leadership development: The current state and future expectations. Consulting Psychology Journal: Practice and Research 60(4): 383-92. https://doi.org/10.1037/10659293.60.4.383

Roberts, C. 2008. Developing future leaders: The role of reflection in the classroom. Journal of Leadership Education 7(1): 116-130. http://www.journalofleadershiped.org/index.php/issues/vol7-iss-1

Rubens, A., G. A. Schoenfeld, B. S. Schaffer and J. S. Leah. 2018. Self-awareness and leadership: Developing an individual strategic professional development plan in an MBA leadership course. International Journal of Management Education 16 1): 1-13. doi: 10.1016/j.jime.2017.11.001.

Ryan, M. 2013. The pedagogical balancing act: Teaching reflection in higher education. Teaching in Higher Education 18(2), 144-155, doi: 10.1080/13562517.2012.694104.

Ryan, M. and M. Ryan. 2013. Theorising a model for teaching and assessing reflective learning in higher education in higher education. Higher Education Research \& Development 32(2): 244-57. doi: 10.1080/07294360.2012.661704.

Schön, D. A. 1983. The reflective practitioner: How professionals think in action. New York: Basic Books, Inc.

Schön, D. A. 1987. Educating the reflective practioner. San Francisco: Jossey-Bass.

Schwandt, T. 2007. The SAGE dictionary of qualitative inquiry. Thousand Oaks California 91320 United States of America: SAGE Publications. Inc. doi: 10.4135/ 9781412986281.

Seale, C. 1999. The quality of qualitative research. Qualitative Injury 5(4): 465-478. doi: $10.1177 / 107780049900500402$

Shamir, B. and G. Eilam. 2005. "What's your story?" A life-stories approach to authentic leadership development. Leadership Quarterly 16(3): 395-417. doi: 10.1016/j.leaqua.2005.03.005.

Shay, S. 2017. Educational investment towards the ideal future: South Africa's strategic choices. South African Journal of Science 113: 1-6.

Sloan, L. and A. Quan-Haase. 2016. The SAGE handbook of social media research methods. City Road, London: SAGE Publications Ltd. doi: 10.4135/9781473983847.

Smith, P. A. C. 2001. Action learning and reflective practices in project environments that are related to leadership development. Management Learning 32(1): 31-48. doi: 10.1177/ 1350507601321003.

Taylor, E. 2007. An update of transformative learning theory: A critical review of the empirical research (1999-2005). International Journal of Lifelong Education 26(2): 173-191. doi: 10.1080/ 02601370701219475.

Vogt, W. P. 2005. Dictionary of statistics and methodology. $3^{\text {rd }}$ Edition. Thousand Oaks, CA: SAGE Publications, Inc. doi: 10.4135/9781412983907.

Zikmund, W. G., B. J. Babin, J. C. Carr and M. Griffin. 2010. Business research methods. $8^{\text {th }}$ Edition. South-Western Cengage Learning. 